\title{
Investigation on Drilling of Banana Fibre Reinforced Composites
}

\author{
Kundan Patel ${ }^{\mathbf{1}, \mathbf{a}}$, \\ ${ }^{1}$ Department of Mechanical Engineering, \\ Charotar University of Science and Technology, \\ Changa-388421, India \\ akundanpatel.me@charusat.ac.in \\ Vijaykumar Chaudhary ${ }^{\mathbf{1 , b}}$ \\ ${ }^{1}$ Department of Mechanical Engineering, \\ Charotar University of Science and Technology, \\ Changa-388421, India \\ bvijaychaudhary.me@charusat.ac.in
}

\author{
Piyush P. Gohil ${ }^{2, c}$ \\ ${ }^{2}$ Department of Mechanical Engineering, \\ The M S University of Baroda, \\ Baroda-390002, India. \\ cpush4679@yahoo.com
}

\author{
Keval Patel ${ }^{3, \mathrm{~d}}$ \\ ${ }^{3}$ Department of Mechanical Engineering, \\ Charotar University of Science and Technology, \\ Changa-388421, India \\ dkevalpatel.me@charusat.ac.in
}

\begin{abstract}
India offered a biggest source of natural fiber like banana, rice husk, coconut and jute fiber etc. All the natural fiber has its unique advantages as well as mechanical properties which are very useful in the development of potential composites for various applications like transportation, automotive etc. There are various machining process in which drilling is most useful process for the assembly of different work pieces. During the drilling of composites it will undergo in the delamination process, which in turn reduces the strength as well as the efficiency of composites materials. In the present work drilling was carried out by using the various feeds $(0.1,0.2,0.3 \mathrm{~mm} / \mathrm{rev})$, speeds $(1000,2000$, $3000 \mathrm{rpm})$ and drill point angles $\left(90^{\circ}, 104^{\circ}, 118^{\circ}\right)$ on the banana polyester reinforced composites. The delamination factor was measured by using machine vision system and digital image analysis. The mathematical model were developed using regression analysis to correlate the various machining parameters with the delamination factor and thrust force. Also the ANOVA has been used to found the effectiveness of the factors as well as their combinations. Optimization has been performed using the desirability function to find out the optimum machining condition for drilling of banana fibre reinforced composites.
\end{abstract}

Keywords-Drilling; Banana Fibre Reinforced Composites; Delamination; Design of experiment; Image analysis; ANOVA; Optimization.

\section{INTRODUCTION}

There has been intense investigation on natural fiber composites in past. These investigations show that natural fiber composites reveal greater properties than conventional composites. Several studies showed that by adding natural fiber reinforcement many properties like strength and stiffness can be improved significantly. The vital thing is the similar separation of fiber for obtaining improved properties. The physical and mechanical properties make these materials appropriate for a comprehensive variation in applications like construction, electronics, automotive and packaging.

Among the common machining methods used for composites, drilling is the most often adopted. Joining of composites are possible by screws, rivets and bolts because the welding is not possible. As composites are anisotropic materials, drilling rises certain problems that can be associated with successive damage in the area around the holes. The most common damages caused by drilling are fibre pull-out, delamination, interlaminar cracking and thermal degradation. Among these damages delamination is the greatest critical. Delamination is defined as "the separation of the layers of material in a laminate".

Numerous methods have been used to measure delamination like scanning electron microscope [1], C-Scan [3] and shop microscope [5,10]. In general a measureable assessment is required in order to assess the effect of the cutting parameters and the geometry of drill tool [1-6].

\section{MATERIAL AND METHODS}

In this study the composite specimen was prepared using general purpose polyester and pure banana fiber which is procured from Sunrise Handmade Paper Pvt. Ltd. Fibers were randomly oriented and $11.85 \%$ weight fraction was obtained. The specimens of $8 \mathrm{~mm}$ thickness were prepared using the hand lay-up process as shown in figure 1(a).

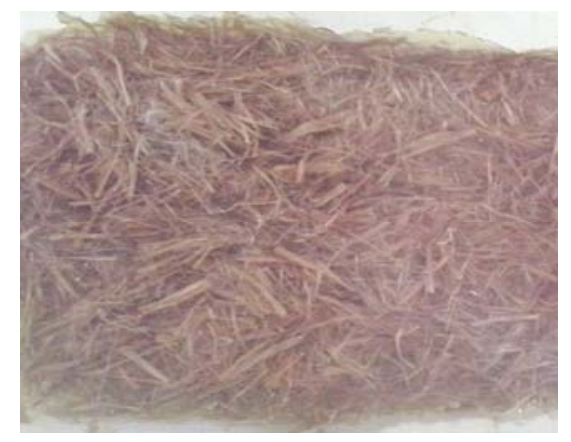

(a) 


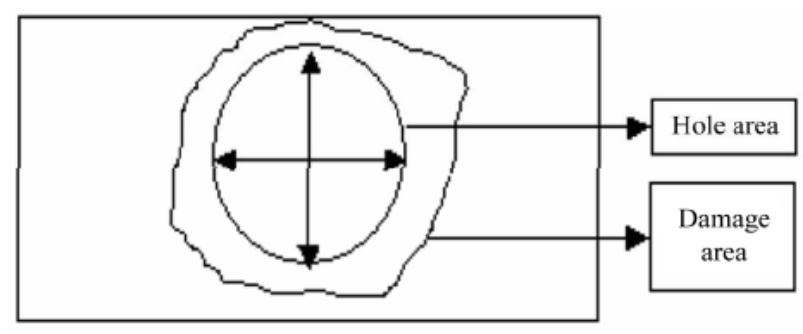

(b)

Fig. 1(a) Prepared specimen of Banana Fibre Reinforced Composite. (b) Delamination.

\section{DESIGN OF EXPERIMENTS}

Design of Experiments (DOE) refers to planning, designing and analysing an Experiment so that valid and objective conclusions can be drawn effectively and efficiently. This design models have been prepared by using the various feeds $(0.1,0.2,0.3 \mathrm{~mm} / \mathrm{rev})$, speeds $(1000,2000$, $3000 \mathrm{rpm})$ and drill point angles $\left(90^{\circ}, 104^{0}, 118^{0}\right)$. Full
Factorial design was used for experimental runs. Drilling tests were carried on CNC vertical machining centre with standard HSS twist drills.

\section{DAMAGE AREA DETERMINATION}

Delamination in the banana-polyester composite was investigated by machine vision technique at entry and exit. The image of damage was taken using a shop microscope Mitutoyo QS - L 2010 ZB. The images were captured by improving contrast to have clear separation of delamination. The damaged area was measured by image analysis using MATLAB programming. The value of the delamination factor (DF) can be calculated using the following equation:

$$
\mathrm{DF}=\mathrm{A}_{\text {damage }} / \mathrm{A}_{\text {hole }}
$$

where $A_{\text {damage }}$ is the maximum area of the damage around the hole periphery ( including hole area ) and $\mathrm{A}$ is the actual hole area as shown in Fig. 2(b).

\section{RESUlTS AND DisCUSSION}

A full factorial design with total no. of 54 experimental runs were carried out. Table 1 shows the results for various experimental runs of drilling.

TABLE 1 EXPERIMENTAL RESULTS.

\begin{tabular}{|c|c|c|c|c|c|c|}
\hline Sr. No & $\begin{array}{l}\text { Point } \\
\text { Angle } \\
\text { (Deg.) }\end{array}$ & $\begin{array}{c}\text { Feed } \\
(\mathrm{mm} / \mathrm{rev})\end{array}$ & $\begin{array}{l}\text { Speed } \\
\text { (rpm) }\end{array}$ & $\begin{array}{l}\text { Thrust } \\
\text { Force } \\
\text { (N.m) }\end{array}$ & DF Entry & DF Exit \\
\hline 1 & 90 & 0.1 & 1000 & 20.5394 & 1.0126 & 1.0039 \\
\hline 2 & 90 & 0.1 & 2000 & 19.0133 & 1.0149 & 1.0019 \\
\hline 3 & 90 & 0.1 & 3000 & 15.9611 & 1.0345 & 1.0261 \\
\hline 4 & 90 & 0.2 & 1000 & 28.1701 & 1.0428 & 1.0223 \\
\hline 5 & 90 & 0.2 & 2000 & 32.7485 & 1.0687 & 1.0589 \\
\hline 6 & 90 & 0.2 & 3000 & 29.6962 & 1.0906 & 1.0562 \\
\hline 7 & 90 & 0.3 & 1000 & 37.3268 & 1.0837 & 1.0790 \\
\hline 8 & 90 & 0.3 & 2000 & 46.4836 & 1.0755 & 1.0877 \\
\hline 9 & 90 & 0.3 & 3000 & 44.9575 & 1.0923 & 1.0733 \\
\hline 10 & 104 & 0.1 & 1000 & 22.0656 & 1.0169 & 1.0371 \\
\hline 11 & 104 & 0.1 & 2000 & 23.5917 & 1.0380 & 1.0476 \\
\hline 12 & 104 & 0.1 & 3000 & 19.0133 & 1.0203 & 1.0566 \\
\hline 13 & 104 & 0.2 & 1000 & 44.9575 & 1.0545 & 1.0552 \\
\hline 14 & 104 & 0.2 & 2000 & 37.3268 & 1.0628 & 1.0590 \\
\hline 15 & 104 & 0.2 & 3000 & 38.8530 & 1.0773 & 1.0607 \\
\hline 16 & 104 & 0.3 & 1000 & 70.9016 & 1.0910 & 1.0873 \\
\hline 17 & 104 & 0.3 & 2000 & 73.9539 & 1.0833 & 1.0635 \\
\hline 18 & 104 & 0.3 & 3000 & 57.1665 & 1.0880 & 1.0330 \\
\hline 19 & 118 & 0.1 & 1000 & 23.5917 & 1.0348 & 1.0164 \\
\hline 20 & 118 & 0.1 & 2000 & 22.0656 & 1.0338 & 1.0260 \\
\hline 21 & 118 & 0.1 & 3000 & 28.1701 & 1.0240 & 1.0340 \\
\hline 22 & 118 & 0.2 & 1000 & 41.9052 & 1.0288 & 1.0358 \\
\hline 23 & 118 & 0.2 & 2000 & 44.9575 & 1.0316 & 1.0357 \\
\hline
\end{tabular}




\begin{tabular}{|c|c|c|c|c|c|c|}
\hline 24 & 118 & 0.2 & 3000 & 40.3791 & 1.0175 & 1.0456 \\
\hline 25 & 118 & 0.3 & 1000 & 63.2710 & 1.0309 & 1.0511 \\
\hline 26 & 118 & 0.3 & 2000 & 52.5881 & 1.0567 & 1.0438 \\
\hline 27 & 118 & 0.3 & 3000 & 58.6926 & 1.0216 & 1.0170 \\
\hline 28 & 90 & 0.1 & 1000 & 23.5917 & 1.0149 & 1.0042 \\
\hline 29 & 90 & 0.1 & 2000 & 17.4872 & 1.0162 & 1.0059 \\
\hline 30 & 90 & 0.1 & 3000 & 15.9611 & 1.0261 & 1.0337 \\
\hline 31 & 90 & 0.2 & 1000 & 34.2746 & 1.0488 & 1.0277 \\
\hline 32 & 90 & 0.2 & 2000 & 31.2223 & 1.0746 & 1.0542 \\
\hline 33 & 90 & 0.2 & 3000 & 32.7485 & 1.0689 & 1.0619 \\
\hline 34 & 90 & 0.3 & 1000 & 37.3268 & 1.0762 & 1.0721 \\
\hline 35 & 90 & 0.3 & 2000 & 44.9575 & 1.0865 & 1.0918 \\
\hline 36 & 90 & 0.3 & 3000 & 46.4836 & 1.0969 & 1.0762 \\
\hline 37 & 104 & 0.1 & 1000 & 25.1178 & 1.0246 & 1.0298 \\
\hline 38 & 104 & 0.1 & 2000 & 28.1701 & 1.0103 & 1.0451 \\
\hline 39 & 104 & 0.1 & 3000 & 20.5394 & 1.0128 & 1.0523 \\
\hline 40 & 104 & 0.2 & 1000 & 44.9575 & 1.0459 & 1.0536 \\
\hline 41 & 104 & 0.2 & 2000 & 40.3791 & 1.0674 & 1.0606 \\
\hline 42 & 104 & 0.2 & 3000 & 37.3268 & 1.0820 & 1.0597 \\
\hline 43 & 104 & 0.3 & 1000 & 67.8494 & 1.0910 & 1.0857 \\
\hline 44 & 104 & 0.3 & 2000 & 69.3755 & 1.0912 & 1.0652 \\
\hline 45 & 104 & 0.3 & 3000 & 58.6926 & 1.0880 & 1.0316 \\
\hline 46 & 118 & 0.1 & 1000 & 22.0656 & 1.0214 & 1.0297 \\
\hline 47 & 118 & 0.1 & 2000 & 25.1178 & 1.0440 & 1.0199 \\
\hline 48 & 118 & 0.1 & 3000 & 26.6439 & 1.0228 & 1.0352 \\
\hline 49 & 118 & 0.2 & 1000 & 48.0097 & 1.0436 & 1.0414 \\
\hline 50 & 118 & 0.2 & 2000 & 43.4313 & 1.0301 & 1.0329 \\
\hline 51 & 118 & 0.2 & 3000 & 46.4836 & 1.0118 & 1.0375 \\
\hline 52 & 118 & 0.3 & 1000 & 67.8494 & 1.0441 & 1.0487 \\
\hline 53 & 118 & 0.3 & 2000 & 58.6926 & 1.0567 & 1.0438 \\
\hline 54 & 118 & 0.3 & 3000 & 64.7971 & 1.0259 & 1.0129 \\
\hline
\end{tabular}

\section{THRUST FORCE}

It is observed through main effect plot for thrust force as shown in fig. 3, the feed have predominant effect on thrust forces. Point angle has quite dominant effect on thrust forces, but speed does not have much effect on thrust forces. The thrust force increases with the increase in the feed. The Thrust force increases suddenly with increase in point angle from $90^{\circ}$ to $104^{0}$, but it almost remains same for the point angle $104^{\circ}$ and $118^{\circ}$. The thrust force decreases with the increase in the speed.

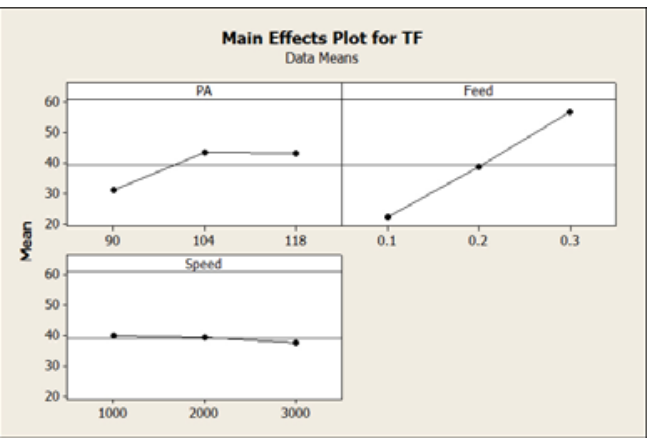

Fig. 3 Main Effect Plot For Thrust Force. 


\section{DELAMINATION FACTOR AT ENTRY AND EXIT}

It is observed through main effect plot for delamination factor at entry as shown in fig. 4(a), the feed has predominant effect on delamination factor at entry, point angle have quite dominant effect on delamination factor at

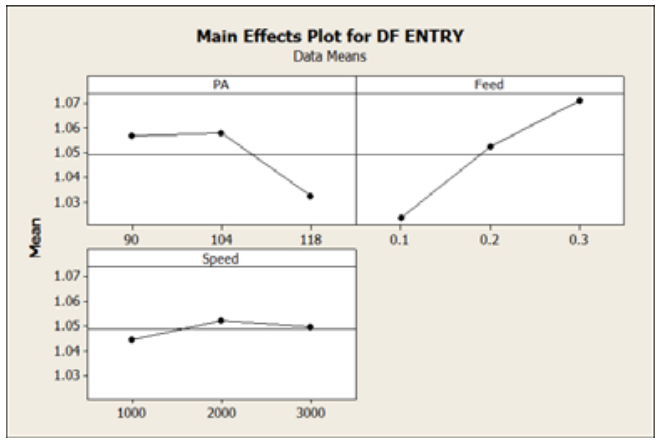

(a) entry and also a speed does not put much effect on delamination factor at entry. The delamination factor at entry decreases with the increase in the point angle. The delamination factor at entry increases with the increase in the feed.

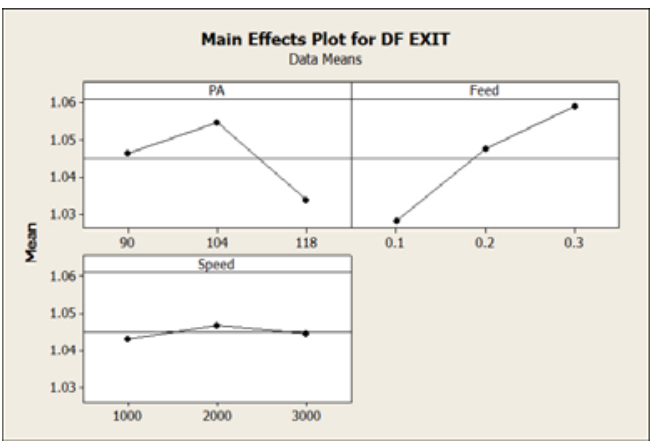

(b)

Fig. 4 (a) Main Effect Plot for Delamination Factor at Entry (b) Main Effect Plot for Delamination Factor at Exit

It is observed through main effect plot for delamination factor at exit as shown in fig.4 (b), the point angle have quire dominant effect on delamination factor at exit, feed have predominant effect on delamination factor at exit, but speed does not have much effect on delamination factor at exit. The delamination factor at exit increases with the increase in the feed and it decreases with the increase in drill point angle and speed. It is observed in fig. 4 (b) that the point angle has a certain effect on the delamination factor at exit.

TABLE 2 ANOVA FOR THRUST FORCE

\begin{tabular}{|c|c|c|c|c|c|c|c|}
\hline Source & DOF & Seq SS & Adj SS & Adj MS & F & P & \% Contribution \\
\hline pa & 2 & 1801.23 & 1801.23 & 900.61 & 148.09 & 0.000 & 13.7108 \\
\hline $\mathrm{f}$ & 2 & 10775.12 & 10775.12 & 5387.56 & 885.90 & 0.000 & 82.0201 \\
\hline S & 2 & 49.77 & 49.77 & 24.89 & 4.09 & 0.028 & 0.3789 \\
\hline Error & 27 & 164.20 & 164.20 & 6.08 & & & 0.09256 \\
\hline Total & 53 & 13941.48 & 6568.58 & & & \\
\hline S = 2.46606 & R-Sq $=98.82 \%$ & R-Sq(adj)=97.69\% \\
\hline
\end{tabular}

TABLE 3 ANOVA FOR DELAMINATION FACTOR AT ENTRY

\begin{tabular}{|c|c|c|c|c|c|c|c|}
\hline Source & DOF & Seq SS & Adj SS & Adj MS & F & P & \%Contribution \\
\hline pa & 2 & 0.0076749 & 0.0076749 & 0.0038374 & 79.41 & 0.000 & 20.6979 \\
\hline $\mathrm{f}$ & 2 & 0.0207209 & 0.0207209 & 0.0103605 & 214.39 & 0.000 & 55.8818 \\
\hline $\mathrm{s}$ & 2 & 0.0005408 & 0.0005408 & 0.0002704 & 5.60 & 0.009 & 1.4581 \\
\hline Error & 27 & 0.0013048 & 0.0013048 & 0.0000483 & & & 0.2605 \\
\hline Total & 53 & 0.0420015 & 0.0420015 & 0.01854 & & & \\
\hline S=0.006951 & R-Sq $=96.89 \% \quad$ R-Sq (adj) $=93.90 \%$ & & \\
\hline
\end{tabular}




\begin{tabular}{|c|c|c|c|c|c|c|c|}
\hline Source & DOF & Seq SS & Adj SS & Adj MS & F & P & \%Contribution \\
\hline pa & 2 & 0.0039924 & 0.0039924 & 0.0019962 & 161.96 & 0.000 & 20.3870 \\
\hline f & 2 & 0.0088650 & 0.0088650 & 0.0044325 & 359.63 & 0.000 & 45.2711 \\
\hline s & 2 & 0.0001119 & 0.0001119 & 0.0000559 & 4.54 & 0.020 & 0.5709 \\
\hline Error & 27 & 0.0003328 & 0.0003328 & 0.0000123 & & & 0.1256 \\
\hline Total & 53 & 0.0270119 & 0.0270119 & 0.009791 & & & \\
\hline S=0.00351073 & \multicolumn{7}{|l}{} \\
\hline
\end{tabular}

From table 2, it can be seen that the point angle and the feed rate factor have statistical and physical significance on the thrust force.

Table 3 shows that the point angle and the feed rate factor have statistical and physical significance on the delamination factor at entry.

Table 4 shows that the point angle and the feed rate factor have statistical and physical significance on the delamination factor at exit.

\section{OPTIMIZATION}

To find the optimal value for point angle, feed, speed we have used the Design Expert 8. The optimization module in searches for a combination of factor levels that simultaneously satisfy the requirements placed on each of the responses and factors.

In optimization, Desirability is an objective function that ranges from zero outside of the limits to one at the goal. The numerical optimization finds a point that maximizes the desirability function.

Based on the optimization performed for thrust force, the optimal value of the thrust force is at $90^{\circ}$ point angle, $3000 \mathrm{rpm}$ cutting speed and $0.1 \mathrm{~mm} / \mathrm{rev}$ feed.

Based on the optimization performed for delamination factor at entry, the optimal value of the delamination at entry is at $90^{\circ}$ point angle, $1000 \mathrm{rpm}$ cutting speed and $0.1 \mathrm{~mm} / \mathrm{rev}$ feed.

Based on the optimization performed for delamination factor at exit, the optimal value of the delamination at exit is at $90^{\circ}$ point angle, $2000 \mathrm{rpm}$ cutting speed and $0.1 \mathrm{~mm} / \mathrm{rev}$ feed.

\section{CONCLUSION}

It is seen that the thrust force increases with increase in the point angle and feed. The thrust force decreases with the increase in the speed. It is seen that the delamination at entry decreases with the increase in the point angle. And the delamination factor at entry increases with the increase in the feed and speed. Also it is observed that the delamination at exit increases with the increase in the feed. And the delamination factor at exit decreases with the increase in the speed and point angle.

The overall optimization has been performed with a goal to optimize the value of thrust force, delamination factor at entry and exit simultaneously. It has been found that the optimal value for thrust force, delamination factor at entry and exit is at $90^{\circ}$ point angle, $1000 \mathrm{rpm}$ cutting speed and $0.1 \mathrm{~mm} / \mathrm{rev}$ feed.

\section{REFERENCES}

[1] D. Chandramohan, K. Marimuthu, International Journal of Advanced Engineering Research and Studies, Vol. 1 (2011) p.134

[2] S. Jayabal, U. Natarajan, U. Sekar, Internetional Journal of Advanced Manufacturing Technology, Vol. 55 (2011) p. 263.

[3] N. Venkateshwaran, A. E. Perumal, Journal of Reinforced Plastics and Composites, Vol. 32 (2013) p.1188.

[4] S. Jaybal, U. Natrajan, Bulletin of Material Science, Vol. 34 (2011) p. 1563.

[5] G. D. Babu, K. S. Babu, B. U. M. Gowd, Journal of Advanced Mechanical Engineering, Vol. 1 (2013) p. 1.

[6] G. D. Babu, K. S. Babu, B. U. M. Gowd, International Journal of Mechanical Engineering Research and Development, Vol. 2 (2012), p. 1.

[7] P. K. Bajpai, I. Singh, Journal of Reinforced Plastics and Composites, Vol. 32 (2013) p.1569.

[8] S. Jaybal, U. Natrajan, International Journal of Advanced Manufacturing Technology, Vol. 51 (2010) p. 371.

[9] D. Bhattacharyya, D. P. W. Horrigan, Composite Science and Technology, Vol. 58 (1998) 267-283.

[10] G. D. Babu, K. S. Babu, B. U. M. Gowd, American Journal of Materials Science and Technology, Vol. 1 (2012) p. 1.

[11] N. K. Sharma, V. Kumar, Journal of Reinforced Plastics and Composites, Vol. 32 (2013) p. 525. 